\title{
O LEGADO DO CÓDIGO CIVIL DE 1916
}

THE LEGACY OF THE 1916 CIVIL CODE

Eduardo Tomasevicius Filho*

\begin{abstract}
Resumo:
Em 2016, a comunidade jurídica brasileira comemora o centenário do Código Civil de 1916, elaborado por Clóvis Beviláqua. Nesse artigo, o autor defende que o Código Civil de 1916, apesar de sua vigência ter ocorrido em um século de profundas transformações políticas, culturais, sociais e econômicas, deixou um legado para o direito brasileiro, ao servir de base para a preservação da tradição jurídica brasileira, tanto por ter absorvido o pensamento oitocentista quanto pelo fato de o Código Civil de 2002 ter recepcionado boa parte dos artigos do Código Civil de 1916.

Palavras-chaves: Codificação. Código Civil brasileiro de 1916. Direito Civil brasileiro. Clóvis Beviláqua. Centenário do Código Civil brasileiro.
\end{abstract}

\begin{abstract}
:
In 2016, the Brazilian legal community celebrates the centennial of the 1916 Civil Code, which draft was prepared by Clóvis Beviláqua. In this paper, the author argues that the 1916 Civil Code, although its force had been in a century with deep political, cultural, social and economic changes, has left a legacy for Brazilian law, serving of basis for the preservation of the Brazilian legal tradition, both by having absorbed the nineteenth century legal thought as the fact that the 2002 Civil Code has carried in much of the 1916 Civil Code.
\end{abstract}

Keywords: Codification. Brazilian 1916 Civil Code. Brazilian Civil Law. Clóvis Beviláqua. Brazilian Civil Code Centennial.

\section{Por que um Código Civil?}

Um dos capítulos mais intrigantes da história do Direito brasileiro é o da codificação civil. Com efeito, levou-se quase um século para que o Brasil tivesse um Código Civil, o qual foi promulgado somente em $1^{\circ}$ de janeiro de 1916. Cem anos após essa data, convém realizar uma avaliação do legado desse fundamental diploma legal do Direito Civil brasileiro, cuja vigência se encerrou com a promulgação do novo Código Civil em 2002. Antes de proceder a essa análise, convém indagar por que se fazia necessário um Código Civil não apenas no Brasil, mas em boa parte dos países durante o século XIX.

\footnotetext{
* Professor Doutor do Departamento de Direito Civil da Faculdade de Direito da Universidade de São Paulo. e-mail: tomaseivcius@usp.br.
} 
Dois eram os principais motivos. O primeiro deles era de ordem política. Devido à crise do Antigo Regime na Europa, revoluções ocorreram na França e na América. Com estas, buscava-se a criação de uma nova ordem social, livre de resquícios de instituições medievais, entre as quais o feudalismo, as corporações de ofício e as dignidades nobiliárquicas. No caso francês, por exemplo, ainda havia a desigualdade entre as pessoas, ${ }^{1}$ pela divisão tripartite dos Estados (status). O clero compunha o primeiro Estado e podia ser proprietário de terras, além de gozar de imunidades tributárias e jurisdicionais. O segundo Estado era a nobreza, que não tinha os mesmos privilégios do clero, mas estava imune da cobrança de tributos. O terceiro Estado, o povo, era formado por um conjunto heterogêneo de pessoas, desde camponeses e vilãos, até profissionais liberais e comerciantes.

Este último grupo, que sustentava os dois primeiros Estados, exigia liberdades, como, por exemplo, aquela para o exercício de atividades econômicas, também conhecida como livre-iniciativa, a qual se deu com a Lei Le Chapelier, ${ }^{2}$ além daquelas de manifestação do pensamento e de imprensa, além do alívio na cobrança de tributos. A propriedade era defendida como um direito sagrado, porque servia de garantia contra o arbítrio do Estado, manifesto pelo domínio eminente do soberano. Como resultado desse processo revolucionário, houve o reconhecimento de que todas as pessoas eram cidadãs, abolindo-se os títulos nobiliárquicos e os privilégios ora existentes, que se deu, por exemplo, com os decretos franceses de 4 e 11 de agosto de $1789 .^{3}$ Nesse contexto,

POTHIER, Robert Joseph. Traité des personnes et des choses. In: OEUVRES de Pothier, contenant les Traités du Droit Français. Nouvelle édition mise en meilleur ordre et publiée par les soins de M. Dupin. Paris: Pichon-Béchet, sucesseur de Beché Ainé, 1825. v. 8, p. 2-5.

2 FRANÇA. Décret relatif aux assemblées d'ouvriers et artisans de même état et proféssion du 14=17 juin 1791. In: DUVERGIER, J. B. (Org.). Collection Complète des Lois, Décrets, Ordonnances, Réglements, Avis du Conseil d'État. 2. ed. Paris: Chez A. Guyot et Scribe, Librairies-Éditeurs, 1834. v. 3. Disponível em: <https://books.google.com.br/books?id=QTg_AAAAcAAJ\&printsec=frontcover\&dq= Collection + Compl $\% \mathrm{C} 3 \% \mathrm{~A} 8$ te + des + Lois,$+\mathrm{D} \% \mathrm{C} 3 \% \mathrm{~A} 9$ crets, + Ordonnances, $+\mathrm{R} \% \mathrm{C} 3 \% \mathrm{~A} 9 \mathrm{glements,},+$ Avis + $\mathrm{du}+$ Conseil $+\mathrm{d} \% \mathrm{E} 2 \% 80 \% 99 \% \mathrm{C} 3 \% 89$ tat $\& \mathrm{hl}=\mathrm{pt}-\mathrm{BR} \& \mathrm{sa}=\mathrm{X} \&$ redir_esc $=\mathrm{y} \# \mathrm{v}=$ onepage $\& \mathrm{q}=$ Collection $\% 20$ Comp1\%C3\%A8te\%20des\%20Lois\%2C\%20D\%C3\%A 9crets\%2C\%20Ordonnances\%2C\%20 R\%C3\%A9glements\%2C\%20Avis\%20du\%20Conseil $\% 20 \mathrm{~d} \% \mathrm{E} 2 \% 80 \% 99 \% \mathrm{C} 3 \% 89$ tat\&f=false>. No caso brasileiro, exemplo da ausência de liberdade no exercício de atividades econômicas foi o alvará de D. Maria I, de Portugal, que proibiu o exercício de várias atividades industriais que concorriam com a mineração, revogado pelo Alvará de D. João VI, de $1^{\circ}$ de abril de 1808. Cf. PORTUGAL (Reino de). Alvará de 5 de janeiro de 1785. Disponível em: <http://www.historiacolonial.arquivonacional.gov.br/Media/Junt\%20 da\%20fazend\%20COD439\%20f27f27vf28.pdf >. E BRASIL. Alvará de $1^{\circ}$ de abril de 1808. Permitte o livre estabelecimento de fabricas e manufacturas no Estado do Brazil. Disponível em: <http://www2.camara. leg.br/legin/fed/alvara/anterioresa1824/alvara-40135-1-abril-1808-572026-publicacaooriginal-95153-pe. html $>$.

3 FRANÇA. Collection Générale des Decrets Rendus par l'Assemblée Nationale avec la mention des sanctions et acceptations donées par le Roi. Paris: L'imprimeur de l'Asamblée Nationale, s.d. t. 1. p. 51-61. Disponível em: <http://gallica.bnf.fr/ark:/12148/bpt6k96685731.r=1789\%20colletion\%20decrets?rk=21459;2>. 
um Código Civil defendia o indivíduo em face do Estado e representava uma nova ordem jurídica, a qual considerava todos iguais perante a lei.

O segundo motivo era de ordem jusfilosófica e estava na tensão entre a pretensão de uma racionalidade jurídica por meio da edição de Códigos e o apego à tradição jurídica, defendida pela denominada "Escola Histórica". Esse fato tornou-se célebre por meio do debate entre Thibaut e Savigny. ${ }^{4}$ Em alguns Estados, o direito era fortemente calcado nas fontes romanas, como no caso de alguns Estados germânicos, e, em certa medida, no Brasil, por meio das Ordenações Filipinas, que mesclavam, neste caso, o Direito Romano com leis e costumes portugueses. O próprio Augusto Teixeira de Freitas contribuiu para a preservação dessa tradição, ao ter elaborado a Consolidação das Leis Civis em 1858, a qual, na prática, foi o Código Civil brasileiro até o advento do Código Civil de 1916. Por outro lado, a codificação civil implicava a apresentação racional dos institutos jurídicos, ${ }^{5}$ em evidente influência jusnaturalista moderna, ${ }^{6}$ para que fosse inaugurado um "novo direito". Tanto que o termo "código", nesse contexto, era o de lei complexa, de apresentação temática de forma sistemática, em oposição às codificações da Antiguidade, como o Código de Hamurábi e os Códigos Gregoriano, Hermogeniano e Teodosiano, que consistiam em meras compilações de leis em sentido formal. ${ }^{7}$

\section{A estrutura do Código Civil de 1916 e suas características}

Sendo a codificação o símbolo de uma nova era, como também o da representação da modernidade em termos legislativos, diversos países, entre os quais as jovens nações latino-americanas, ansiavam pela reforma de seus direitos por meio desses diplomas legais. No caso brasileiro, em especial, tornava-se imprescindível a codificação, porque as Ordenações Filipinas, vigentes no Brasil Império por meio da Lei de 20 de outubro de $1823,{ }^{8}$ eram o direito da antiga metrópole. Por isso, a Constituição política

$4 \quad$ THIBAUT, Anton Friedrich Justus. La codificación. Una controversia programática basada en sus obras "Sobre la necesidad de un derecho civil general para Alemania" y" De la vocación de nuestra época para la legislación y la ciencia del derecho". Con adiciones de los autores y juicios de sus contemporáneos. Introducción y selección de textos de Jacques Stern. Traducción del alemán de José Díaz García. [Madrid]: Aguilar, [1970]. (Precede al tít.: Thibaut y Savigny).

5 DOMAT, Jean. Les loix civiles dans leur ordre naturel et legum delectus. Paris: Chez Michel Brunet, 1713. Disponível em: $<$ https://books.google.com.br/books?id=xydGAAAAcAAJ\&printsec=frontcover\&dq=D OMAT,+Jean.+Les+loix+civiles+dans+leur+ordre+naturel+et+legum+delectus\&hl=pt-BR\&sa=X\&redir esc $=\mathrm{y} \# \mathrm{v}=$ onepage $\& \mathrm{q}=$ DOMAT $\% 2 \mathrm{C} \% 20 \mathrm{Jean} . \% 20$ Les $\% 201$ oix $\% 20$ civiles $\% 20$ dans $\% 201$ eur $\% 20$ ordre $\% 20$ naturel $\% 20$ et $\% 20$ legum $\% 20$ delectus $\& \mathrm{f}=$ false $>$.

6 WIEACKER, Franz. História do direito privado moderno. Tradução de A. M. Botelho Hespanha. 3. ed. Lisboa: Fundação Calouste Gulbenkian, 2004. p. 234.

7 GILISSEN, John. Introdução histórica ao direito. Tradução de A. M. Hespanha e L. M. Macaísta Malheiros. 2. ed. Lisboa: Fundação Calouste Gulbenkian, 1995. p. 91.

8 BRASIL. Lei de 20 de outubro de 1823. Declara em vigor a legislação pela qual se regia o Brazil até 25 de 
brasileira de 1824, à semelhança de outras congêneres latino-americanas, ordenava o seguinte no art. 179, XVIII: “Organizar-se-ha quanto antes um Codigo Civil, e Criminal, fundado nas solidas bases da Justiça, e Equidade". 9

Em relação ao Direito Penal, o Código Criminal do Império foi promulgado com relativa rapidez em 1830, para substituir o Livro V das Ordenações Filipinas, cujas sanções eram severíssimas, entre as quais as penas de morte e de degredo para o Brasil... Elaborado a partir da síntese de projetos de Clemente Pereira e de Bernardo Pereira de Vasconcelos, e aprimorado durante os debates legislativos, era muito avançado para a época, por ter acolhido ideias iluministas, sobretudo as de Beccaria e de Jeremy Bentham. O Código Criminal brasileiro acabou servindo de modelo para o Código Criminal espanhol de 1848 , e este, por sua vez, influenciou a codificação criminal na América Latina. ${ }^{10}$

Em se tratando do Direito Civil no Brasil - como se sabe - a primeira tentativa de codificação deu-se apenas na década de 1860, após se ter concluído a Consolidação das Leis Civis, com o Esboço de Código Civil, de Augusto Teixeira de Freitas, cujo projeto serviu de base para o Código Civil argentino, de Dalmacio Velez Sarsfield. Posteriormente, Nabuco de Araújo tentou realizar um anteprojeto de Código Civil, sem sucesso. O Visconde de Seabra, autor do projeto que resultou no Código Civil português, também se ofereceu para elaborar um Código Civil brasileiro. Do mesmo modo, Joaquim Felício dos Santos e Antonio Coelho Rodrigues elaboraram projetos de Código Civil, que tramitaram no parlamento, mas que também ficaram pelo caminho. As pesquisas jus-historiográficas mais atualizadas ${ }^{11}$ noticiam que estes projetos não se tornaram Direito Positivo por questões políticas, bem como pela rivalidade existente entre os juristas para que o seu projeto fosse o vitorioso, com o intuito de escrever o próprio nome na história do Direito brasileiro.

Enfim, quis o destino que os louros da codificação fossem atribuídos a Clóvis Beviláqua. Este jurista, à época do convite formulado para a realização deste

Abril de 1821 e bem assim as leis promulgadas pelo Senhor D. Pedro, como Regente e Imperador daquella data em diante, e os decretos das Cortes Portuguezas que são especificados. Disponível em: $<$ http://www2. camara.leg.br/legin/fed/lei_sn/anterioresa1824/lei-40951-20-outubro-1823-574564-publicacaooriginal97677-pe.html>.

9 BRASIL. Constituição Política do Império do Brasil, elaborada por um Conselho de Estado e outorgada pelo Imperador D. Pedro I, em 25 de março de 1824. Disponível em: <http://www.planalto.gov.br/ccivil_03/ Constituicao/Constituicao24.htm>.

10 POVEDA VELASCO, Ignacio Maria; TOMASEVICIUS FILHO, Eduardo. O código criminal do império do Brasil de 1830 e sua real originalidade. In: SILVEIRA, Renato de Mello Jorge; GOMES, Mariângela Gama de Magalhães (Org.). Estudos em homenagem a Ivette Senise Ferreira. São Paulo: LiberArs, 2015. p. 251-272.

11 GOMES, Patricia Regina Mendes Mattos Corrêa. Pensamento e ação de Joaquim Felício dos Santos: um projeto de Código Civil oitocentista. 2015. Dissertação (Mestrado) - Faculdade de Direito, Universidade de São Paulo, São Paulo, 2015. 
trabalho, era professor da Faculdade de Direito do Ceará, e já tinha produção doutrinária não apenas em Direito Civil, ${ }^{12}$ mas também em outras áreas do direito e na literatura. ${ }^{13}$ Era ligado à "Escola do Recife", liderada por Tobias Barreto, a qual produzia um pensamento crítico para os padrões da época, afiliando-se ao pensamento alemão oitocentista, ao cientificismo e ao evolucionismo darwiniano. ${ }^{14}$ Clóvis Beviláqua, no entanto, afastava-se ligeiramente do pensamento de seus mestres e reconhecia a importância da socialidade em detrimento do individualismo e liberalismo. Influenciado por Rudolf von Jhering, ${ }^{15}$ observa-se em Clóvis Beviláqua o apreço pela função social dos institutos jurídicos, como no caso da função social do contrato, descrita em sua obra "Direito das Obrigações" como instrumento de conciliação de interesses colidentes e de pacificador de egoísmos em luta, afirmador da individualidade humana e apto à aproximação dos povos. ${ }^{16}$ Quanto à família, Clóvis Beviláqua seguia os doutrinadores romanos, ao mesmo tempo que se apoiava em Herbert Spencer e em historiadores brasileiros, como Rocha Pombo e Varnhagen. ${ }^{17}$

Entretanto, o Código Civil foi um produto de seu tempo e este diploma legal acabou consolidando as principais "forças resultantes" em termos de organização social, das quais Clóvis Beviláqua, assim como os demais autores de projetos de Código Civil dificilmente podiam escapar. Na elaboração do projeto de Código Civil, Clóvis Beviláqua inspirou-se nos projetos anteriores, bem como na experiência alemã, o que lhe permitiu realizar o seu trabalho em seis meses. ${ }^{18}$

Em termos estruturais, desenvolveu-se, no Brasil, a partir de Teixeira de Freitas, a ideia de que se deveria dividir o Código Civil em Parte Geral e Parte Especial sendo questionável, portanto, a afirmação de que o Código Civil de 1916 se teria deixado influenciar pelo Código Civil alemão na adoção de uma parte geral - e que a legislação privatista deveria ser unificada em um único Código, que abrangesse os direitos civil e comercial. Clóvis Beviláqua manteve a divisão entre Parte Geral e Parte Especial, mas

12 Cf. BEVILÁQUA, Clóvis. Direito das obrigações. Bahia: Fonseca Magalhães, 1896; Direito da família. Recife: Ramiro M. Costa, 1896; Resumo das licções de legislação comparada sobre o direito privado. 2. ed. Bahia: Magalhães, 1897; Direito das sucessões. Bahia: Fonseca Magalhães, 1899.

13 Cf. BEVILÁQUA, Clóvis. Criminologia e direito. Bahia: Fonseca Magalhães, 1896; Juristas philosophos. Bahia: Magalhães, 1897; Épochas e individualidades: estudos literários. 2. ed. Rio de Janeiro: Garnier, 1888; Thesouro da Juventude. Rio de Janeiro: W. M. Jackson, s.d.

14 MACHADO NETO, Antônio Luiz. História das idéias jurídicas no Brasil. São Paulo: Editorial Grijalbo, EDUSP, 1969. p. 80.

15 MACHADO NETO, Antônio. Luiz. História das idéias ... cit., p. 118.

16 BEVILÁQUA, Clóvis. Direito das obrigações. cit., p. 154-155.

17 Cf. BEVILÁQUA, Clóvis. Direito da família. cit., p. 18, 24, 38, 40, 41, 45.

18 MEIRA, Sílvio Augusto de Bastos. Clóvis Beviláqua. Sua vida. Sua obra. Fortaleza: Edições Universidade Federal do Ceará, 1990. p. 146-147. 
recusou promover a unificação do Direito Privado, por meio de um único Código de Direito Privado. ${ }^{19}$

Quanto à redação dos artigos do Código Civil, observam-se diferenças entre o Código Civil de Beviláqua em relação aos projetos anteriores. Ao contrário do projeto de Joaquim Felício dos Santos, cuja redação dos artigos era bastante detalhada, Clóvis Beviláqua optou por uma redação sintética, com artigos curtos. Aliás, a redação dos artigos foi pretexto para que Rui Barbosa tivesse feito campanha contra a escolha de Clóvis Beviláqua como responsável pela elaboração do Código Civil. Tais críticas entraram para a história do Direito como "folclóricas", por destacarem mais os aspectos formais do projeto em detrimento dos aspectos substanciais ou dos institutos jurídicos. ${ }^{20}$

Em relação ao conteúdo dos livros, a Parte Geral era baseada, em linhas gerais, na pandectística alemã, a qual já estava recepcionada na doutrina brasileira, como se pode observar, por exemplo, na obra de Antonio Joaquim Ribas ${ }^{21}$ e na do próprio Clóvis Beviláqua. ${ }^{22}$ Acerca do início da personalidade jurídica, ele expôs a opinião dominante naquele tempo - de que o nascimento era fato decisivo, razão pela qual a personalidade jurídica se dava com o nascimento com vida - embora, pessoalmente, Clóvis Beviláqua entendesse que se deveria iniciar com a concepção. ${ }^{23}$ Ele também estava a par das teorias sobre pessoas jurídicas e dos desenvolvimentos da matéria por Teixeira de Freitas e no Código Civil alemão, evidenciando o entendimento de que pessoa jurídica era um instrumento para a realização de fins humanos. ${ }^{24}$ Adotou a teoria do negócio jurídico, denominando-o, entretanto, como ato jurídico e inseriu cláusula geral de responsabilidade civil subjetiva, inspirada no art. 1.382 do Código Civil francês.

No tocante à Parte Especial, a ordem dos livros variava de um projeto para outro. Projetos anteriores adotavam como critério a matéria mais abstrata em primeiro lugar, de modo que o livro sobre obrigações fosse o primeiro deles na Parte Especial. Já Clóvis Beviláqua escolheu a ordem do pessoal - iniciando com Direito de Família - ao patrimonial, terminando com o Direito das Sucessões. ${ }^{25}$

19 BEVILÁQUA, Clóvis. Em defeza do projecto de código civil brasileiro. Rio de Janeiro: Livraria Francisco Alves, 1906. p. 33.

20 BARBOSA, Rui. Parecer sobre a redação do Código Civil. Reimpressão das Obras Completas de Rui Barbosa. Rio de Janeiro: Ordem dos Advogados do Brasil - Seção do Estado do Rio de Janeiro e Fundação Casa de Rui Barbosa, 1982.

21 Cf. RIBAS, Antônio Joaquim. Curso de direito civil brasileiro. Brasília: Senado Federal, Conselho Editorial, 2003. v. 2. (Edição fac-similar da 2. Ed. de 1880).

22 Cf. BEVILÁQUA, Clóvis. Teoria geral do direito civil. 4. ed. Brasília: Ministério da Justiça, 1972.

23 BEVILÁQUA, Clóvis. Teoria geral do direito civil. cit., p. 70-73.

24 BEVILÁQUA, Clóvis. Teoria geral do direito civil. cit., p. 133.

25 BEVILÁQUA, Clóvis. Em defeza do projecto de código civil brasileiro. cit., p. 49-50. 
O livro de Direito de Família pouca inovação trouxe ao Direito brasileiro. Embora este fosse de importância indiscutível, porque representava a recepção do direito de família para o Direito Civil, devido à separação entre Estado brasileiro e Igreja Católica, seu conteúdo ainda preservava a essência do Direito Canônico. Muito do que se define como Direito de Família era regido pelo Concílio de Trento, de observância obrigatória no Brasil por meio das Constituições Primeiras do Arcebispado da Bahia, de 1707. ${ }^{26}$ Em breve síntese, as diretrizes do Direito Canônico de Família eram as seguintes: a primeira delas era o matrimônio como sacramento, instituição destinada à procriação, razão pela qual se instituíram regras de impedimentos matrimoniais, que vedavam uniões das quais pudessem resultar filhos com malformação congênita ou aqueles não decorrentes da união não advinda do matrimônio. A segunda delas era a distinção entre filhos legítimos, nascidos de pais casados, e filhos ilegítimos. Na definição contida no Livro IV, Tit. 93, das Ordenações Filipinas, eram aqueles provindos de "coito damnado e punível". Eram filhos, portanto, de relações entre concubinos, adúlteros e religiosos, denominados, respectivamente, de filhos naturais, incestuosos e sacrílegos. ${ }^{27}$ A terceira era a indissolubilidade do matrimônio e a consequente proibição do divórcio, posto que “o que Deus uniu, o homem não separa". ${ }^{28}$ Por fim, a quarta diretriz era a proibição do matrimônio entre pessoas de religiões diversas da religião católica.

A despeito de terem sido promulgadas leis importantes relativas ao Direito de Família ao longo do século XIX, entre as quais a de 2 de setembro de 1847, que, no art. $2^{\circ}$, permitia o reconhecimento de filhos ilegítimos antes do casamento, assim como o Decreto n. 1.144, de 11 de setembro de 1861, sobre casamento entre pessoas de religião diversa da do Império brasileiro, devido à imigração no Brasil e, por fim, o Decreto n. 181, de 1890, que regulava o casamento civil, mas mantinha as mesmas características do casamento canônico e a proibição do divórcio, o Código Civil de 1916 acabou conservando a visão da época, preservando, portanto, a tradição católica em vez de rompê-la. Clóvis Beviláqua até reconhecia a necessidade de igualdade entre cônjuges, ainda que sob a liderança do homem, mas o texto promulgado estabelecia a incapacidade

26 VIDE, Sebastião Monteiro da. Constituições primeiras do Arcebispado da Bahia: feitas, e ordenadas pelo illustrissimo, e reverendíssimo senhor D. Sebastião Monteiro da Vide 5. Arcebispo do dito Arcebispado, e do Conselho de Sua Magestade. Brasília: Senado Federal, Conselho Editorial, 2007. Cf. BRASIL. Decreto de 3 de novembro de 1827. Declara em effectiva observancia as disposições do Concilio Tridentino e da Constituição do Arcebispado da Bahia sobre matrimonio. Disponível em: <http://www2.camara.leg.br/ legin/fed/decret_sn/1824-1899/decreto-38408-3-novembro-1827-566712-publicacaooriginal-90232-pl. html>.

27 PEREIRA, Lafayette Rodrigues. Direitos de família. Brasília: Senado Federal, Conselho Editorial: Superior Tribunal de Justiça, 2004. (Edição fac-similiar). p. 254.

28 Mc. $10,9$. 
relativa da mulher por efeito do casamento, ${ }^{29}$ assim como a necessidade de autorização do marido para o exercício de profissão.

Mantiveram-se no Código Civil de 1916 as distinções entre filhos legítimos e ilegítimos e a proibição do divórcio. Permitia-se, contudo, que o casal pudesse desquitarse dos deveres do casamento, o que resultava na separação do casal, mas não dissolvia o vínculo entre eles, impedindo-os de formar uma nova família. Clóvis Beviláqua confessava ter oscilado em sua opinião, porque, num primeiro momento, era favorável ao instituto, mas, depois de ter meditado sobre a questão, mudara de posicionamento, alegando que o divórcio seria nefasto por ofender o costume do povo brasileiro, a respeitabilidade da família brasileira e a honestidade das mulheres. ${ }^{30}$

Para o Direito das Coisas, a propriedade foi regulada nos moldes estabelecidos no Código Civil francês, diferenciando-se do direito anterior, que reconhecia o domínio direto e domínio útil e sesmarias. Adotou-se a obrigatoriedade de transcrição da escritura pública no registro imobiliário para a efetivação da alienação de direitos reais sobre imóveis. Aproximou-se, pois, do modelo alemão, afastando-se da concepção dos efeitos limitados da transcrição, previstos no art. $8^{\circ}, \S 4^{\circ}$, do Decreto n. 169-A, de 19 de janeiro de $1890 .{ }^{31}$ A disciplina da aquisição originária da propriedade e dos direitos reais sobre coisa alheia seguia a sistemática do Direito Romano, tais como os direitos de vizinhança e servidões, exceto quanto ao usufruto, que deixou de ser reconhecido como servidão pessoal para tornar-se instituto jurídico autônomo. É importante destacar que o Código Civil de 1916 disciplinava a propriedade literária em seu bojo - embora já houvesse uma lei de direitos autorais de $1898 .^{32}$

No que concerne às obrigações, encontra-se uma "teoria geral das obrigações contratuais e extracontratuais”. Devido ao caráter liberal do Código - por ser mais um produto do século XIX do que do século XX - não se previa a boa-fé nem a revisão contratual por onerosidade excessiva, decorrente da modificação das circunstâncias existentes no momento da celebração do negócio. Entre os contratos em espécie, a locação

29 "Olhemos de frente a natureza e amoldemol-a ás necessidades sociaes, sem desvirtual-a. ella nos está claramente dizendo que indivíduos diferentemente conformados estão destinados a funcções diferentes. $\mathrm{Na}$ família, deve a mulher gozar de direitos eguaes aos do homem, cabendo-lhe uma esfera de acção própria, distincta, porém harmônica com a de seu marido. Mas, sendo a família uma organização social, deve ter uma direção, e essa só póde ser confiada ao homem (...)".BEVILÁQUA, Clóvis. Em defeza do projecto de código civil brasileiro. Rio de Janeiro: Livraria Francisco Alves, 1906. p. 95.

30 BEVILÁQUA, Clóvis. Direito da família. cit., p. 286-287.

31 BRASIL. Decreto n. 169-A, de 19 de janeiro de 1890. Substitue as leis n. 1237 de 24 de setembro de 1864 e n. 3272 de 5 de outubro de 1885. Disponível em: <http://www.planalto.gov.br/ccivil_03/decreto/1851-1899/ D169-A.htm>. Art. $8^{\circ}, \S 4^{\circ}$ : "A transcripção não induz a prova do dominio, que fica salvo a quem for".

32 Cf. BRASIL. Lei n. 496, de $1^{\circ}$ de agosto de 1898. Define e garante os direitos autoraes. Disponível em: $<$ http://www2.camara.leg.br/legin/fed/lei/1824-1899/lei-496-1-agosto-1898-540039-publicacaooriginal39820-pl.html>. 
de serviços procurava disciplinar as relações de trabalho numa sociedade que passava por um primeiro ciclo de industrialização, sobretudo em São Paulo, com o uso de mão de obra imigrante, além do trabalho no campo, por meio da parceria rural. Ademais, o legislador civil valorizou as artes, por meio dos contratos de edição e de representação dramática.

Quanto ao Direito das Sucessões, reconheceu-se a igualdade entre descendentes legítimos e filhos naturais reconhecidos, tal como já havia na legislação; reduziu-se a transmissão da herança até colaterais de sexto grau e não mais de décimo grau e colocou-se o cônjuge supérstite como terceiro na ordem de vocação hereditária e não mais em último lugar, ${ }^{33}$ como se previa no art. 981 da Consolidação das Leis Civis.

\section{As modificações do Código Civil de 1916 ao longo do século XX}

Todo Código Civil tem a pretensão de regular a sociedade por décadas, ou, se possível, por séculos. Porém, o século XIX foi aquele em que ocorreram as maiores transformações sociais em tão curto período de tempo desde então. Houve duas fortes crises econômicas mundiais, sendo a primeira devido à quebra da Bolsa de Valores de Nova Iorque em 1929, que simbolizou a derrocada do liberalismo econômico, e a segunda, na década de 1970, devido ao aumento vertiginoso do preço do barril de petróleo, com a formação da Organização dos Países Exportadores de Petróleo - OPEP. As péssimas condições sociais implicaram revoluções socialistas, algumas bem-sucedidas, outras não. Duas grandes guerras mundiais aconteceram e uma nova ordem mundial, polarizada entre Estados Unidos e União Soviética, substituiu a hegemonia anglofrancesa. $\mathrm{O}$ mundo se dividiu em duas partes por quarenta anos e muitas tantas outras guerras regionais aconteceram, motivadas, muitas vezes, por essa disputa geopolítica. Alterou-se a divisão internacional do trabalho, de modo que determinados países tidos como subdesenvolvidos, tiveram grandes processos de industrialização, com a instalação de filiais de grandes corporações. De qualquer modo, reconheceu-se a necessidade de superação da desigualdade substancial entre as pessoas, a qual não se podia camuflá-la mais por meio da igualdade formal. A dignidade da pessoa humana, a solidariedade e justiça sociais ganharam força no Direito Internacional e encontraram suporte no Direito Constitucional - daí terem surgido o Direito Civil Constitucional e o reconhecimento da eficácia horizontal dos direitos fundamentais - motivadas pelas redações dos artigos iniciais da Constituição Italiana e da Lei Fundamental de Bonn. Os Estados retomaram o protagonismo na organização social, por meio de leis de ordem pública e por políticas de bem-estar social.

33 BEVILÁQUA, Clóvis. Em defeza do projecto de código civil brasileiro. cit., p. 151. 
O Código Civil de 1916, consequentemente, sofreu o impacto de todas essas transformações. O ramo do Direito Civil que se conservou praticamente intacto durante sua vigência foi o Direito das Sucessões. Já em matéria de direitos reais, pouca coisa do texto original mudou, mas houve a complementação desse ramo do direito por meio de leis especiais, entre as quais a lei sobre condomínios edilícios e incorporações imobiliárias (Lei n. 4.591/1964), a alienação fiduciária em garantia, regulada inicialmente pelo art. 66 da Lei do Mercado de Capitais (Lei n. 4.728/1965) e, posteriormente, pelo Decreto-Lei n. 911/1969, aplicada para proporcionar o financiamento de bens de consumo duráveis, como no caso dos automóveis. Do mesmo modo, alterou-se parcialmente o regime de hipotecas com o Decreto-Lei n. 70/1966, como meio de viabilizar o financiamento imobiliário, que somente se consolidou com a Lei n. 9.514/1997, sobre alienação fiduciária para imóveis, vigente até os dias atuais. A propriedade literária foi retirada do Código Civil pela Lei de Direitos Autorais (Lei n. 5.988/1973, posteriormente revogada pela atual Lei n. 9.610/1998). A ideia de função social da propriedade não foi suficientemente forte para afetar o conceito de propriedade. Nem mesmo o Estatuto da Terra (Lei n. 4.501/1964) ou a Constituição Federal de 1988 lograram modificar substancialmente o conteúdo desse instituto jurídico.

No Direito das Obrigações, o primeiro aspecto a ser destacado é que as relações de trabalho reguladas pela locação de serviços saíram do âmbito do Direito Civil e tornaram-se um novo ramo do direito: o Direito do Trabalho. O segundo aspecto foi o advento do denominado "dirigismo contratual", pelo qual o Estado passou a intervir diretamente na relação contratual para a proteção da parte mais fraca. Nesse sentido, na década de 1930, promulgou-se a lei da usura (Decreto n. 22.626/1933), a lei sobre locação comercial (Decreto n. 24.150/1934) e a lei sobre compromisso de compra e venda de imóveis a prazo (Decreto-lei n. 58/1937), com o intuito de proteger o comprador em face do vendedor que se recusava a lavrar a escritura definitiva de compra e venda ao final do pagamento do preço, por meio da ação de adjudicação compulsória. Este tema foi completado posteriormente pela Lei n. 6.766/1979, sobre parcelamento do solo urbano. Também escapou do Direito Civil a locação de imóveis urbanos por meio de várias leis sucessivas (Decreto-Lei n. 4.598/1942, Decreto-Lei n. 9.969/1946, Lei n. 1.300/1950, Lei n. 4.464/1964, Lei n. 6.649/1979 e a vigente Lei n. 8.245/1991). O ápice da proteção da parte mais fraca deu-se em 1990 com a promulgação do Código de Defesa do Consumidor (Lei n. 8.078/1990). Contudo, a impossibilidade de revisão contratual foi um dos grandes problemas existentes no Direito das Obrigações, tendo em vista que o Brasil vivenciou, por décadas, elevadíssimas taxas de inflação. Não se alterou o Código Civil nem se promulgou lei específica sobre o tema até o advento do Código de Defesa do Consumidor. Assim, os tribunais brasileiros aplicavam a teoria da imprevisão para o restabelecimento do equilíbrio contratual. 
Para obrigações extracontratuais, importa destacar a cláusula geral de responsabilidade civil do art. 159, do Código Civil de 1916, cuja amplitude permitia, com sucesso, a solução dos mais variados problemas relativos a danos, ainda que somente com a Constituição Federal de 1988 é que se reconheceu, com tranquilidade, a indenização do dano moral. Porém, a responsabilidade objetiva, que já se alinhavava antes mesmo da promulgação do Código Civil, com o Decreto n. 2.681/1912, sobre a responsabilidade civil das estradas de ferro, permanecia a latere do Código Civil. Promulgaram-se leis especiais sobre responsabilidade objetiva em matéria de acidentes nucleares (Lei n. 6.453/1977) e de danos ambientais (Lei n. 6.938/1981), bem como a responsabilidade objetiva do Estado, no art. $37, \S 6^{\circ}$, da Constituição Federal, e a responsabilidade objetiva em relações de consumo, com o Código de Defesa do Consumidor.

Mas foi no Direito de Família que se verificou a erosão do Código Civil de 1916. As transformações sociais, as mudanças de costumes e o maior reconhecimento da igualdade entre cônjuges, fizeram com que importantes leis fossem promulgadas para modificar ou derrogar o Código Civil logo em suas primeiras décadas de vigência. Por exemplo, o Decreto-Lei n. 3.200/1941, destinado à proteção da família, permitiu o casamento entre colaterais em terceiro grau. Pelo Decreto-Lei n. 4.737/1942, admitiuse o reconhecimento de filhos ilegítimos após o término da sociedade conjugal e, pela Lei n. 883/1949, concedeu-se ação de reconhecimento de paternidade após o término da sociedade conjugal do pai.

Na década de 1960, houve o primeiro abalo da estrutura do Direito de Família no Código Civil. Esse fato ocorreu com a promulgação do Estatuto da Mulher Casada (Lei n. 4.121/1962), que, por meio de alterações no Código Civil, pôs fim à incapacidade relativa da mulher que contraísse núpcias. Deu a elas mais autonomia, pela permissão para litigar sem autorização do marido e, sobretudo, aboliu a necessidade de autorização do marido para exercício de profissão, ao ter definido que os frutos civis do trabalho ou indústria de cada cônjuge não entravam mais na comunhão de bens do casal, escapando, assim, da administração do marido enquanto chefe da família.

O segundo abalo deu-se com a permissão para o divórcio, devido à luta do Sen. Nelson Carneiro para aprovar a Emenda Constitucional n. 9, de 1977, a qual aboliu a indissolubilidade do casamento, existente desde a Constituição de 1934, permitindo, a partir de então, a separação nos termos da lei. Meses após, aprovou-se a Lei do Divórcio (Lei n. 6.515/1977), que suprimiu o desquite e inseriu a figura da separação judicial como estágio preparatório para o divórcio, além de ter alterado o regime legal, de comunhão universal de bens para comunhão parcial de bens. Vale destacar que, em 1964, o Supremo Tribunal Federal editou as súmulas ns. 380 e 382, que foram marcos importantes para a proteção das concubinas, garantindo-se a elas a partilha do patrimônio adquirido 
com o esforço comum e a desnecessidade de vida em comum sob o mesmo teto para o reconhecimento judicial dessa relação familiar.

O terceiro grande abalo deve-se à Constituição Federal de 1988, a qual, no art. 226, aboliu a distinção entre filhos legítimos e ilegítimos. Reconheceu-se a união estável e a família monoparental como entidades familiares dignas de proteção do Estado e ampliaram as hipóteses de divórcio. Em seguida, em 1992, promulgou-se lei sobre investigação de paternidade de maneira ampla (Lei n. 8.560/1992), regularam-se os alimentos e a sucessão da companheira (Lei n. 8.970/1994), bem como a união estável, reconhecida no art. 226, § $3^{\circ}$, da Constituição Federal, pela Lei n. 9.278/1996. Com efeito, muito pouco sobrara do Direito de Família no Código Civil de 1916. Na prática, o Direito de Família tornara-se Direito Constitucional.

\section{Considerações finais: o legado do Código Civil de 1916 para o direito}

Mesmo entre tantas transformações pelas quais o Direito Civil passou ao longo do século XX, que requereram alterações do texto original e a promulgação de diversas leis especiais, o Código Civil de 1916 deixou sim um legado para o Direito brasileiro.

Assim como o texto elaborado por Clóvis Beviláqua representava a síntese do Direito Civil projetado no século XIX, ao terem-se aproveitado os trabalhos anteriores na sua elaboração, o Código Civil de 2002, em última análise, é o Código Civil de 1916 atualizado até o fim do século XX. Essa atualização se deu com a recepção, no Código Civil de 2002, da disciplina jurídica dos direitos da personalidade, a indenização por danos morais de forma ampla, a inserção de uma cláusula geral de responsabilidade civil objetiva baseada no risco e outra sobre abuso do direito, o ajuste das regras sobre prescrição e decadência, a possibilidade de revisão contratual em caso de onerosidade excessiva, a harmonização das hipóteses de usucapião com a Constituição Federal, a recepção do compromisso de compra e venda e da alienação fiduciária em garantia como direitos reais e a filiação decorrente da reprodução humana assistida, tudo em adição ao texto-base do Código Civil de 1916. Não houve a modificação estrutural das matérias, tal como aconteceu com o novo Código de Processo Civil de 2015 em relação ao Código anterior, de 1973. Nem mesmo houve alterações redacionais, que foram objeto de críticas de Rui Barbosa. Boa parte dos artigos do Código Civil de 2002 são exatamente os artigos do Código Civil de 1916.

Ademais, pelo fato de o Código Civil de 1916 ter tido como alicerces as produções jurídicas de juristas brasileiros de escol, entre os quais Augusto Teixeira de Freitas, consolidou-se uma tradição jurídica brasileira em matéria de Direito Civil, tanto ao permitir que esta não se perdesse com o Código Civil de 1916, quanto por ter 
possibilitado que essa chegasse aos dias atuais por meio do Código Civil de 2002. Sendo certo que uma codificação civil é elemento importante da formação da identidade jurídica e cultural de um país, tal como o Código Civil francês de 1804, ou Code Napoléon, e o Código Civil alemão (BGB), de 1896, que continuam em vigor até hoje, apesar de modificações substanciais, como no caso da Schuldmodernisierungsgesetz de 2002 e a reforma recente do direito francês dos contratos, de 2016, o Brasil pode dizer que tem uma tradição jurídica própria devido ao Código Civil de 1916. Porém, com a promulgação do Código Civil de 2002, perdeu-se a oportunidade de ter no Código Civil de Clóvis Beviláqua o que os franceses denominam de "lugar de memória", ${ }^{34}$ isto é, um símbolo da cultura de um povo, tal como o Code Napoléon o é dentro da cultura francesa.

São Paulo, 29 de janeiro de 2016.

\section{Referências}

BARBOSA, Rui. Parecer sobre a redação do Código Civil. Reimpressão das Obras Completas de Rui Barbosa. Rio de Janeiro: Ordem dos Advogados do Brasil - Seção do Estado do Rio de Janeiro e Fundação Casa de Rui Barbosa, 1982.

BEVILÁQUA, Clóvis. Criminologia e direito. Bahia: Fonseca Magalhães, 1896.

. Direito da família. Recife: Ramiro M. Costa, 1896.

. Direito das obrigações. Bahia: Fonseca Magalhães, 1896.

. Direito das sucessões. Bahia: Fonseca Magalhães, 1899.

. Em defeza do projecto de código civil brasileiro. Rio de Janeiro: Livraria Francisco Alves,

1906.

. Épochas e individualidades: estudos literários. 2. ed. Rio de Janeiro: Garnier, 1888.

. Juristas philosophos. Bahia: Magalhães, 1897.

. Resumo das licções de legislação comparada sobre o direito privado. 2. ed. Bahia: Magalhães, 1897.

. Teoria geral do direito civil. 4. ed. Brasília: Ministério da Justiça, 1972.

. Thesouro da Juventude. Rio de Janeiro: W. M. Jackson, s.d.

34 CARBOnNIER, Jean. Le code civil. In: NORA, Pierre. (Org.). Les lieux de mémoire. Paris: Gallimard, 1986. v. 2, p. 293-315. 
BRASIL. Alvará de $1^{\circ}$ de abril de 1808. Permitte o livre estabelecimento de fabricas e manufacturas no Estado do Brazil. Disponível em: <http://www2.camara.leg.br/legin/fed/alvara/anterioresa1824/ alvara-40135-1-abril-1808-572026-publicacaooriginal-95153-pe.html>.

- Constituição Política do Império do Brasil, elaborada por um Conselho de Estado e outorgada pelo Imperador D. Pedro I, em 25 de março de 1824. Disponível em: <http://www. planalto.gov.br/ccivil_03/Constituicao/Constituicao24.htm>.

. Decreto de 3 de novembro de 1827. Declara em effectiva observancia as disposições do Concilio Tridentino e da Constituição do Arcebispado da Bahia sobre matrimonio. Disponível em: $<$ http://www2.camara.leg.br/legin/fed/decret_sn/1824-1899/decreto-38408-3-novembro-1827566712-publicacaooriginal-90232-pl.html>.

. Decreto n. 169-A, de 19 de janeiro de 1890. Substitue as leis n. 1237 de 24 de setembro de 1864 e n. 3272 de 5 de outubro de 1885. Disponível em: <http://www.planalto.gov.br/ccivil_03/ decreto/1851-1899/D169-A.htm>.

. Lei de 20 de outubro de 1823. Declara em vigor a legislação pela qual se regia o Brazil até 25 de abril de 1821 e bem assim as leis promulgadas pelo Senhor D. Pedro, como Regente e Imperador daquella data em diante, e os decretos das Cortes Portuguezas que são especificados. Disponível em: $<$ http://www2.camara.leg.br/legin/fed/lei_sn/anterioresa1824/lei-40951-20-outubro-1823-574564publicacaooriginal-97677-pe.html>.

. Lei $n$. 496, de $1^{\circ}$ de agosto de 1898. Define e garante os direitos autoraes. Disponível em: $\quad<$ http://www2.camara.leg.br/legin/fed/lei/1824-1899/lei-496-1-agosto-1898-540039publicacaooriginal-39820-pl.html $>$.

CARBONNIER, Jean. Le code civil. In: NORA, Pierre. (Org.). Les lieux de mémoire. Paris: Gallimard, 1986. v. 2, p. 293-315.

DOMAT, Jean. Les loix civiles dans leur ordre naturel et legum delectus. Paris: Chez Michel Brunet, 1713. Disponível em: <https://books.google.com.br/books?id=xydGAAAAcAAJ\&prints ec $=$ frontcover\&dq=DOMAT, + Jean.+ Les + loix + civiles + dans + leur + ordre + naturel + et + legum + delec tus \&hl=pt-BR\&sa $=X \&$ redir_esc $=y \# v=$ onepage $\& \mathrm{q}=$ DOMAT $\% 2 \mathrm{C} \% 20 \mathrm{Jean} . \% 20 \mathrm{Les} \% 201 \mathrm{loix} \% 20$ civiles\%20dans $\% 20$ leur\%20ordre\%20naturel $\% 20$ et $\% 20$ legum $\% 20$ delectus $\& \mathrm{f}=$ false $>$.

FRANÇA. Collection Générale des Decrets Rendus par l'Assemblée Nationale avec la mention des sanctions et acceptations donées par le Roi. Paris: L'imprimeur de l'Asamblée Nationale, s.d. t. 1. p. 51-61. Disponível em: <http://gallica.bnf.fr/ark:/12148/bpt6k96685731.r=1789\%20colletion\%20 decrets? $\mathrm{rk}=21459 ; 2>$.

. Décret relatif aux assemblées d'ouvriers et artisans de même état et proféssion du 14=17 juin 1791. In: DUVERGIER, J. B. (Org.). Collection Complète des Lois, Décrets, Ordonnances, Réglements, Avis du Conseil d'État. 2. ed. Paris: Chez A. Guyot et Scribe, Librairies-Éditeurs, 1834. v. 3. Disponível em: <https://books.google.com.br/books?id=QTg_AAAAcAAJ\&printse $\mathrm{c}=$ frontcover $\& \mathrm{dq}=$ Collection $+\mathrm{Compl} \% \mathrm{C} 3 \% \mathrm{~A} 8 \mathrm{te}+\mathrm{des}+$ Lois $,+\mathrm{D} \% \mathrm{C} 3 \% \mathrm{~A} 9 \mathrm{crets},+$ Ordonnances,+ 
R\%C3\%A9glements, +Avis + du + Conseil + d $\%$ E2\%80\%99\%C3\%89tat\&hl=pt-BR\&sa $=$ X\&redir esc $=y \# v=$ onepage \& $\mathrm{q}=$ Collection $\% 20 \mathrm{Compl} \% \mathrm{C} 3 \% \mathrm{~A} 8 \mathrm{te} \% 20 \mathrm{des} \% 20 \mathrm{Lois} \% 2 \mathrm{C} \% 20$ D\%C3\%A9crets\%2C\%20Ordonnances\%2C\%20R\%C3\%A9glements\%2C\%20Avis\%20du\%20 Conseil $\% 20 \mathrm{~d} \% \mathrm{E} 2 \% 80 \% 99 \% \mathrm{C} 3 \% 89$ tat $\& \mathrm{f}=$ false $>$.

GILISSEN, John. Introdução histórica ao direito. Tradução de A. M. Hespanha e L. M. Macaísta Malheiros. 2. ed. Lisboa: Fundação Calouste Gulbenkian, 1995.

GOMES, Patricia Regina Mendes Mattos Corrêa. Pensamento e ação de Joaquim Felício dos Santos: um projeto de Código Civil oitocentista. 2015. Dissertação (Mestrado) - Faculdade de Direito, Universidade de São Paulo, São Paulo, 2015.

MACHADO NETO, Antônio Luiz. História das idéias jurídicas no Brasil. São Paulo: Editorial Grijalbo, EDUSP, 1969.

MEIRA, Sílvio Augusto de Bastos. Clóvis Beviláqua. Sua vida. Sua obra. Fortaleza: Edições Universidade Federal do Ceará, 1990.

PEREIRA, Lafayette Rodrigues. Direitos de família. Brasília: Senado Federal, Conselho Editorial: Superior Tribunal de Justiça, 2004. (Edição fac-similiar).

PORTUGAL(Reino de). Alvaráde 5 dejaneiro de 1785. Disponível em: $<$ http://www.historiacolonial. arquivonacional.gov.br/Media/Junt\%20da\%20fazend\%20COD439\%20f27f27vf28.pdf>.

POTHIER, Robert Joseph. Traité des personnes et des choses. In: OEUVRES de Pothier, contenant les Traités du Droit Français. Nouvelle édition mise en meilleur ordre et publiée par les soins de M. Dupin. Paris: Pichon-Béchet, sucesseur de Beché Ainé, 1825. v. 8.

POVEDA VELASCO, Ignacio Maria; TOMASEVICIUS FILHO, Eduardo. O código criminal do império do Brasil de 1830 e sua real originalidade. In: SILVEIRA, Renato de Mello Jorge; GOMES, Mariângela Gama de Magalhães (Org.). Estudos em homenagem a Ivette Senise Ferreira. São Paulo: LiberArs, 2015.

RIBAS, Antônio Joaquim. Curso de direito civil brasileiro. Brasília: Senado Federal, Conselho Editorial, 2003. v. 2. (Edição fac-similar da 2. Ed. de 1880).

THIBAUT, Anton Friedrich Justus. La codificación. Una controversia programática basada en sus obras "Sobre la necesidad de un derecho civil general para Alemania" y" De la vocación de nuestra época para la legislación y la ciencia del derecho". Con adiciones de los autores y juicios de sus contemporáneos. Introducción y selección de textos de Jacques Stern. Traducción del alemán de José Díaz García. [Madrid]: Aguilar, [1970]. (Precede al tít.: Thibaut y Savigny).

VIDE, Sebastião Monteiro da. Constituições primeiras do Arcebispado da Bahia: feitas, e ordenadas pelo illustrissimo, e reverendíssimo senhor D. Sebastião Monteiro da Vide 5. Arcebispo do dito Arcebispado, e do Conselho de Sua Magestade. Brasília: Senado Federal, Conselho Editorial, 2007. 
WIEACKER, Franz. História do direito privado moderno. Tradução de A. M. Botelho Hespanha. 3. ed. Lisboa: Fundação Calouste Gulbenkian, 2004. 